\title{
Effects of Preharvest Precipitation, Air Temperature, and Humidity on the Occurrence of Soft Scald in 'Honeycrisp' Apples
}

\author{
Renae E. Moran ${ }^{1}$ \\ Department of Plant, Soil and Environmental Sciences, University of Maine, \\ P.O. Box 179, Monmouth, ME 04259
}

Jennifer R. DeEIl

Ontario Ministry of Agriculture, Food and Rural Affairs, P.O. Box 587, Simcoe, Ontario, Canada N3Y 4N5

\author{
William Halteman \\ Department of Mathematics and Statistics, University of Maine, 5752 Neville \\ Hall, Orono, ME 04469
}

Additional index words. Malus $\times$ domestica, disorders, postharvest

\begin{abstract}
The relationship of soft scald incidence (SSI) with precipitation, temperature, and fruit maturity indicators in 'Honeycrisp' apples was examined using 7 years of data in Maine and 6 years in Ontario, Canada. Relative humidity was also examined in Maine. Soft scald incidence was highly variable from year to year ranging from $1 \%$ to $85 \%$ in Maine and from $0 \%$ to $76 \%$ in Ontario. In Ontario, SSI was negatively related to soluble solids at harvest (partial $r^{2}=0.50 ; P=0.0041$ ) and negatively related to precipitation during 90 to 120 days from bloom (DFB; partial $\left.r^{2}=0.28 ; P=0.0344\right)$. In Maine, SSI was most strongly related to precipitation in the 90 to $120 \mathrm{DFB}\left(\right.$ partial $\left.r^{2}=0.53 ; P=0.0001\right)$, maximum air temperature 60 to $90 \mathrm{DFB}$ (partial $r^{2}=0.21 ; P=0.0001$ ), and number of hours when relative humidity was greater than $85 \%$ (partial $\left.r^{2}=0.11 ; P=0.0001\right)$.
\end{abstract}

'Honeycrisp' is a popular cultivar that is currently being planted in large numbers in northern regions of the United States and Canada. 'Honeycrisp' is highly susceptible to soft scald, a chilling disorder characterized by sharply defined browning of the skin and underlying tissue. To prevent this disorder, special postharvest treatment such as delayed cooling and/or storage temperatures are necessary to minimize losses. Methods used to prevent soft scald are not always effective and can lead to other disorders and quality loss (Watkins et al., 2005), which could limit production of this cultivar.

Received for publication 27 Jan. 2009. Accepted for publication 21 July 2009.

Maine Ag. and Forestry Experiment Station number 3041 .

Funded by the New England Tree Fruit Research Committee, the Maine Agricultural Center, and the University of Maine Agricultural and Forest Experiment Station.

We thank Ian Nichols, Gaétan Bourgeois, Dominique Plouffe, and the Norfolk Fruit Growers' Association for assistance in collecting the Ontario weather data.

Mention of a trademark, proprietary product, or vendor does not constitute a guarantee or warranty of the product nor does it imply approval or disapproval to the exclusion of other products or vendors that may also be suitable.

${ }^{1}$ To whom reprint requests should be addressed; e-mailrmoran@umext.maine.edu.
In susceptible cultivars, soft scald develops within a few weeks to months on placement in cold storage and is more severe at temperatures below $3{ }^{\circ} \mathrm{C}$ (Brooks and Harley, 1934). Storing fruit at temperatures above $2.5{ }^{\circ} \mathrm{C}$ reduces the incidence and is recommended for prevention (Magness and Burroughs, 1923; Meheriuk et al., 1994) but is not consistently effective in 'Honeycrisp' (DeLong et al., 2004; Watkins et al., 2005). In addition, storage temperature above $3{ }^{\circ} \mathrm{C}$ can lead to quality loss and may also necessitate separate storage facilities when other cultivars require colder storage temperatures (Watkins et al., 2005).

Susceptibility to soft scald increases with later harvest dates (Tong et al., 2003; Watkins et al., 2004). As a result, harvest at earlier stages of maturity, when starch index is below 6.0, is recommended for prevention (Greene and Weis, 2001). However, harvesting at an earlier stage of maturity is not always effective in preventing soft scald (DeLong et al., 2004; Watkins et al., 2005). In addition, when fruit are harvested early to prevent soft scald, flavor may not be sufficiently developed for high consumer appeal (Wargo and Watkins, 2004).

Soft scald varies considerably in its occurrence from year to year and appears to vary in severity between different growing regions in 'Honeycrisp' (Watkins et al., 2004) and 'Jonathan' apples (Plagge and Maney, 1937). Severity can range from most or all of the fruit being afflicted to few or none in other instances (DeLong et al., 2004; Wargo and Watkins, 2004). The cause of this variability remains unknown. Environmental variables such as temperature and orchard management such as nutrition have been implicated in predisposing fruit to disorders (Autio et al., 1986; Ferguson et al., 1999; Smock, 1977), but the role of these factors in the development of soft scald has not been established. Elucidating environmental and orchard factors could allow growers to predict soft scald occurrence and to subsequently make harvest and storage decisions that minimize losses. The objective of this study was to evaluate the influence of preharvest environmental variation in temperature and precipitation on the occurrence of soft scald in 'Honeycrisp' apples.

\section{Materials and Methods}

In Maine, 7 years of data were collected on the occurrence of soft scald incidence (SSI) in one orchard at the Maine Agricultural and Forest Experiment Station in Monmouth, ME. In Ontario, Canada, 1 year of data were collected in Orchards 1, 3, and 4 and 5 years in Orchard 2. Orchards 1 and 2 were located near Simcoe, Orchard 3 near Toronto, and Orchard 4 near Collingwood, Ontario.

Accumulated precipitation, mean air temperature, and accumulated growing degree days (GDDs) above a base of $7{ }^{\circ} \mathrm{C}$ in the 0 to 30,30 to 60,60 to 90 , and 90 to $120 \mathrm{~d}$ after bloom (DFB) were analyzed for significant relationships with the occurrence of soft scald after cold storage using stepwise multiple linear regression. The number of hours when relative humidity during the same periods was greater than $85 \%$ was included in the Maine analysis, but relative humidity data from Ontario were not available. Mean air temperature, total precipitation, and total GDDs from the entire period of full bloom to harvest were eliminated from the final analysis because of duplicity problems and the low amount of variability explained by each.

The amount of precipitation in Maine was measured daily using a garden-variety rain gauge except in 2002, when data were obtained from the National Oceanic and Atmospheric Administration (NOAA) station at the Augusta State Airport located 15 miles from the orchard. Data collected from the rain gauge were compared with the same NOAA station for accuracy. Air temperature in Maine was recorded hourly by an electronic data logger, Model CR10X (Campbell Scientific, Logan, UT). Temperature was measured with an HMP45C platinum resistance temperature detector and relative humidity with a Humicap 180 capacitive sensor (Model HMP45C; Vaisala, Woburn, MA). The weather station was located at the experiment station in a location near the orchard.

In Ontario, weather data for Orchards 1 and 2 were obtained from Weather Innovations Inc. (Chatham, Ontario, Canada), which maintained a weather station in Orchard 2. For 2007 and 2009, temperature data were 
obtained from the Canadian National Climate Archive stations in Hamilton. Data for Orchards 3 and 4 were taken from the Canadian National Climate Archive stations in Toronto and Parry Sound Harbour, respectively.

Harvest dates, starch index, internal ethylene at harvest, and incidence of soft scald are listed in Table 1. Fruit were harvested in the middle of the harvest period for 'Honeycrisp' when it was assumed that fruit would be susceptible to soft scald. Starch index was in the range of 5.2 to 7.8 and internal ethylene concentration ranged from 0 to $32 \mu \mathrm{L} \cdot \mathrm{L}^{-1}$. Soft scald incidence was highly variable from year to year ranging from a low of $1 \%$ to a high of $85 \%$ in Maine and from $0 \%$ to $76 \%$ in Ontario.

Starch index and internal ethylene were measured on a total of 10 fruit per orchard each year. Soluble solids concentration was measured using a handheld temperaturecompensated refractometer (Fisher Scientific, Nepean, Ontario, Canada) on fruit in Ontario, but not in Maine. Starch staining with iodine was measured using a visual rating in which $1=$ all starch remaining and $8=$ no starch (Blanpied and Silsby, 1992). To measure internal ethylene concentration (IEC) in Maine, a 25-mm-long stainless steel needle with a syringe was inserted through the calyx end to remove $1 \mathrm{~mL}$ of gas, which was injected into a gas chromatograph with a flame ionization detector (Shimadzu GC-8A, Kyoto, Japan). The gas chromatograph was fitted with a $450 \times 3$-mm stainless steel column packed with activated alumina. Operating conditions were as follows: oven temperature was $80^{\circ} \mathrm{C}$, injector temperature was $200{ }^{\circ} \mathrm{C}$, and flame ionization detector temperature was $200{ }^{\circ} \mathrm{C}$. IEC was measured in Ontario by withdrawing a 3-mL gas sample from the core of each fruit using a syringe and injecting the sample into a Varian CP-3800 gas chromatograph (Varian Canada Inc.,
Mississauga, Ontario, Canada) equipped with a $0.5-\mathrm{mL}$ sample loop, flame ionization detector, and $15 \mathrm{~m} \times 0.32-\mathrm{mm}$ Restek RtSPLOT $^{\mathrm{TM}}$ capillary column (Chromatographic Specialties Inc., Brockville, Ontario, Canada). The injector, column, and detector temperatures were 120,35 , and $225{ }^{\circ} \mathrm{C}$, respectively. High-grade helium was used as the carrier gas at a flow rate of $0.37 \mathrm{~mL} \cdot \mathrm{s}^{-1}$ with a typical run time of $2 \mathrm{~min}$.

In Maine, fruit were placed in cold storage within $3 \mathrm{~h}$ of harvest and stored at 0 to $1{ }^{\circ} \mathrm{C}$ for 4 to 5 months in 2002 to 2005 and for 2 to 3 months in 2006 to 2008 . Apples were held in Ontario at 0 to $1{ }^{\circ} \mathrm{C}$ or $3{ }^{\circ} \mathrm{C}$ for 5 months in 2002 to 2007 and for 3 months in 2008 . Apples from Orchard 4 in 2008 were held overnight at $10{ }^{\circ} \mathrm{C}$ and then placed in cold storage. Otherwise, Ontario apples were placed in cold storage within several hours of harvest. After removal from cold storage, each fruit surface was inspected for signs of soft scald.

The orchard in Maine had five replications with four trees in each replication. It was planted in 1994, and the rootstock was M.26 EMLA. Fifty fruit were harvested from each replication and were stored as a composite sample, but fruit from different replications were kept separate during storage and analysis. Orchards in Ontario were planted in 1998 to 1999 on rootstocks M.26 and M.7. A minimum of three replicate boxes with 50 fruit in each was harvested from four to five trees in each orchard each year. Replications in Ontario were pooled in most years, so only the means of each year and orchard were used in the analysis.

To determine which variables explained most of the year-to-year variation in SSI, temperature, humidity, and precipitation variables were subjected to stepwise multiple linear regression using a $P$ value of 0.15 and an increase in $r^{2}$ of at least $10 \%$ for each additional variable included in the model.

Table 1. Maturity at harvest and soft scald incidence (SSI) of 'Honeycrisp' apples from orchards used for relationships with precipitation, air temperature, growing degree days ${ }^{z}$, and relative humidity.

\begin{tabular}{|c|c|c|c|c|c|c|}
\hline Orchard & Harvest date & $\begin{array}{l}\text { Starch } \\
\text { index }\end{array}$ & $\begin{array}{l}\text { Internal ethylene } \\
\text { concn }\left(\mu \mathrm{L} \cdot \mathrm{L}^{-1}\right)\end{array}$ & SSC (\%) & $\mathrm{SSI}(\% \pm \mathrm{SE})$ & $\begin{array}{c}\text { Storage } \\
\text { temp }\left({ }^{\circ} \mathrm{C}\right)\end{array}$ \\
\hline \multicolumn{7}{|c|}{ Maine } \\
\hline 1 & 25 Sept. 2002 & 6.9 & 6.8 & - & $30 \pm 4$ & 1.4 \\
\hline 1 & 29 Sept. 2003 & 7.8 & 31.7 & - & $1 \pm 1$ & 1.2 \\
\hline 1 & 1 Oct. 2004 & 5.9 & 0.0 & - & $84 \pm 7$ & 0.7 \\
\hline 1 & 27 Sept. 2005 & 6.7 & 0.0 & - & $57 \pm 8$ & 0.6 \\
\hline 1 & 15 Sept. 2006 & 7.0 & 8.4 & - & $26 \pm 2$ & 1.3 \\
\hline 1 & 22 Sept. 2007 & 7.2 & 11.2 & - & $85 \pm 3$ & 1.3 \\
\hline 1 & 25 Sept. 2008 & 6.9 & 8.6 & - & $35 \pm 10$ & 1.1 \\
\hline \multicolumn{7}{|c|}{ Ontario } \\
\hline 1 & 11 Sept. 2002 & 5.7 & 1.4 & 13.7 & 40 & $0-1$ \\
\hline 2 & 10 Sept. 2004 & 7.4 & 2.4 & 14.4 & 0 & 0 \\
\hline 2 & 10 Sept. 2004 & 7.4 & 2.4 & 14.4 & 13 & 3 \\
\hline 2 & 15 Sept. 2005 & 5.2 & 9.8 & 13.2 & 6 & $0-1$ \\
\hline 2 & 15 Sept. 2006 & 7.0 & 29.7 & 14.0 & 1 & $0-1$ \\
\hline 2 & 12 Sept. 2007 & 7.2 & 1.9 & 14.3 & 18 & 3 \\
\hline 2 & 16 Sept. 2008 & 5.4 & 11.4 & 12.9 & 29 & 0.5 \\
\hline 3 & 19 Sept. 2008 & 7.2 & 9.9 & 12.4 & 76 & 0.5 \\
\hline 4 & 26 Sept. 2008 & 7.0 & 32.1 & 13.7 & 2 & 0.5 \\
\hline
\end{tabular}

${ }^{\mathrm{z}}$ Degree days above a base temperature of $7{ }^{\circ} \mathrm{C}$.

${ }^{\mathrm{y}} \mathrm{Starch}$ index of $1=$ complete starch staining and $8=$ no staining with iodine.

$\mathrm{SSC}=$ soluble solids concentration
The REG procedure and the STEPWISE selection method of SAS Version 9.1 (SAS Institute, Inc., Cary, NC) were used to conduct this analysis. The RSREG procedure was used to analyze one nonlinear variable. The final model was tested for normality and plots of residuals versus predicted values were examined to confirm a constant variance and linearity.

\section{Results and Discussion}

Stepwise regression identified three variables that explained a significant portion of the variability in SSI in Maine (Table 2). The final selected model was:

$$
\begin{aligned}
\mathrm{Y}= & 675-1.00 * \mathrm{P}_{90-120 \mathrm{DFB}}-15.5 * \\
& \mathrm{MT}_{60-90 \mathrm{DFB}}-0.21 * \mathrm{RH}_{0-60 \mathrm{DFB}}
\end{aligned}
$$

$\left(r^{2}=0.86 ; P=0.0001\right)$ where $\mathrm{P}$ is precipitation during 90 to $120 \mathrm{DFB}$, MT is average maximum temperature 60 to 90 $\mathrm{DFB}$, and $\mathrm{RH}$ is the number of hours when relative humidity was greater than $85 \%$ from bloom to $60 \mathrm{~d}$ after. High humidity during 0 to $30 \mathrm{DFB}$ and during 30 to $60 \mathrm{DFB}$ were included as significant variables in the stepwise regression with a similar negative relationship to SSI, but neither alone accounted for at least $10 \%$ of the variability. Stepwise regression was redone with total hours of high humidity for the period of 0 to $60 \mathrm{DFB}$, and this accounted for $11 \%$ of the additional variation. For each hour increase of high humidity during the 2-month period after bloom, SSI decreased at a rate of $0.2 \%$ when other variables were held constant. During 0 to $60 \mathrm{DFB}, 608$ to $775 \mathrm{~h}$ of high humidity occurred. Precipitation during the 90 to 120 $\mathrm{DFB}$, which ranged from 64 to $160 \mathrm{~mm}$, accounted for the greatest amount of year-toyear variation in SSI based on the partial $r^{2}$ of $53 \%$. This relationship was negative implying a greater incidence in years with less precipitation. Soft scald decreased at a rate of $1 \%$ for each $1-\mathrm{mm}$ increase in precipitation in the month before harvest when the other two variables were held constant. Maximum temperature 60 to 90 DFB ranged from 23 to 28 ${ }^{\circ} \mathrm{C}$ and was negatively related to SSI (partial $\left.r^{2}=0.21 ; P=0.0001\right)$. For each $1^{\circ}$ increase in average maximum temperature during 60 to 90 DFB, SSI decreased at a rate of $15.5 \%$ when the other two variables were held constant.

As a result of the high degree of multicollinearity, the final selected variables were not the only variables to explain a significant portion of variability in SSI. The best single factor was precipitation during 30 to $60 \mathrm{DFB}$ as linear and quadratic variables $\left(r^{2}=0.69\right.$; $P=0.0001)$. This relationship was nonlinear with maximum SSI occurring when $80 \mathrm{~mm}$ of precipitation occurred and lower SSI when precipitation was above and below this with a total range of 36 to $138 \mathrm{~mm}$. However, stepwise regression failed to include these as significant indicating that other variables appeared to be more important. 
Table 2. Multiple linear regression statistics of air temperature and precipitation with soft scald incidence at varying time periods in days from bloom (DFB) in Ontario and also including relative humidity in Maine.

\begin{tabular}{|c|c|c|c|}
\hline Variable & Time period & Partial $r^{2}$ & Parameter estimate \\
\hline \multicolumn{4}{|c|}{ Maine } \\
\hline Intercept & - & - & $716 * * *$ \\
\hline Precipitation & 90 to $120 \mathrm{DFB}$ & $0.53 * * * \mathrm{z}$ & $-1.0 * * *$ \\
\hline Maximum temperature & 60 to $90 \mathrm{DFB}$ & $0.21 * * *$ & $-15.5^{* * *}$ \\
\hline $\begin{array}{l}\text { Hours of relative humidity } \\
\text { greater than } 85 \%\end{array}$ & 0 to $60 \mathrm{DFB}$ & $0.11 * * *$ & $-0.2 * * *$ \\
\hline \multicolumn{4}{|c|}{ Ontario } \\
\hline Intercept & - & - & 562 \\
\hline Soluble solids concn & Harvest & $0.50 *$ & $-37.2 * *$ \\
\hline Precipitation & 90 to $120 \mathrm{DFB}$ & $0.28 *$ & $-0.50 *$ \\
\hline
\end{tabular}

z***,**,*Significance at the $P=0.001,0.01$, and 0.05 level, respectively.

Stepwise linear regression of Ontario data indicated only two variables that explained a significant portion of variability in SSI. The final selected model was:

$$
\begin{aligned}
\mathrm{Y}= & 562-0.50 * \mathrm{P}_{90-120 \mathrm{DFB}}-37 * \\
& \operatorname{SSC}\left(r^{2}=0.77 ; P=0.0119\right)
\end{aligned}
$$

where $\mathrm{P}$ is precipitation during 90 to 120 DFB and SSC is fruit soluble solids at harvest. Soluble solids accounted for $50 \%$ of the variation in SSI. Soluble solids concentration was negatively related to SSI and decreased at a rate of $37 \%$ for each increase in fruit SSC of $1 \%$ when precipitation was held constant. Precipitation in the 90 to 120 DFB was negatively related to SSI, which was similar to Maine but accounted for a smaller proportion of variability, $28 \%$. With each 1-mm increase in precipitation, SSI decreased at a rate of $0.5 \%$, assuming a constant SSC.

The significant linear relationships with SSI in this study do not demonstrate causality and should be confirmed with controlled studies. This study did not include light measurements, so it cannot be confirmed that temperature, humidity, and precipitation are the sole environmental factors involved in year-to-year variation. In addition, the time periods examined in this study were arbitrarily selected, but other durations and intervals could also be important.

Precipitation during the weeks before harvest was more important than earlier in the season suggesting that precipitation during the maturation phase may influence susceptibility to SSI. It was not apparent if trees were suffering from water stress because plant water status was not measured, but periods of dry weather occurred in Maine that led to dry soil conditions. The effect of precipitation on SSI may be indirect through its effect on plant water status and other physiological parameters such as fruit maturity
(Ebel et al., 1993) and respiration (Harding, 1929) or other unknown effects on fruit physical traits. The results of this study are limited to precipitation measurements, but future research should include plant water status and other plant factors affected by environmental variables.

In this study, fruit were harvested in the middle part of the commercial harvest, so the difference in maturity was not likely the major cause for year-to-year variation in SSI. Increase in SSI resulting from later harvest dates in Maine was not substantial in the 3 years in which it was measured, and the difference was smaller than the year-to-year variability. In 2003, SSI increased from $1 \%$ to $5 \%$ with harvest $8 \mathrm{~d}$ later, from $41 \%$ to $55 \%$ with harvest $4 \mathrm{~d}$ later in 2005 , and from $26 \%$ to $36 \%$ with harvest $10 \mathrm{~d}$ later in 2006.

The significant relationship to precipitation and temperature in this study is limited to average SSI values within a season and does not explain much of the tree-to-tree variability. For example, SSI in individual trees ranged from $31 \%$ to $69 \%$ in 2005 and from $2 \%$ to $87 \%$ in 2008 in Maine. These trees received similar amounts of precipitation and were exposed to similar temperatures during each growing season, but had fruit with widely varying SSI. The results in this study cannot account for this type of variation.

Preharvest precipitation was the only factor that explained SSI variation in both locations. In Maine, precipitation appeared to be more important than temperature or relative humidity and in Ontario was the only environmental factor that was related to SSI. Preharvest environmental variables were related to SSI, but further research is needed to confirm this under controlled conditions and to tie environmental variables to physiological causes of soft scald. Elucidating preharvest factors that contribute to soft scald may increase our ability to predict its occurrence and to understand the underlying physiological causes.

\section{Literature Cited}

Autio, W.R., W.J. Bramlage, and S.A. Weis. 1986 Predicting poststorage disorders of 'Cox's Orange Pippin' and 'Bramley's Seedling' apples by regression equations. J. Amer. Soc. Hort. Sci. 111:738-742.

Blanpied, G.D. and K. Silsby. 1992. Predicting harvest date windows for apples. Cornell Univ., Ithaca, NY. Info. Bul. 221.

Brooks, C. and C.P. Harley. 1934. Soft scald and soggy break-down of apples. J. Agr. Res. 49:55-69.

DeLong, J.M., R.K. Prange, and P.A. Harrison. 2004. The Influence of pre-storage delayed cooling on quality and disorder incidence in 'Honeycrisp' apple fruit. Postharvest Biol. Technol. 34:353-358.

Ebel, R.C., E.L. Proebsting, and M.E. Patterson. 1993. Regulated deficit irrigation may alter apple maturity, quality, and storage life. HortScience 28:141-143.

Ferguson, I., R. Volz, and A. Woolf. 1999. Preharvest factors affecting physiological disorders of fruit. Postharvest Biol. Technol. $15: 255-262$.

Greene, D.W. and S.A. Weis. 2001. Evaluation and growing of Honeycrisp in New England. Compact Fruit Tree 34:100-103.

Harding, P.L. 1929. Respiration studies of Grimes apple under various controlled temperatures. Proc. Amer. Soc. Hort. Sci. 26:319-324.

Magness, J.R. and A.M. Burroughs. 1923. Studies in apple storage. In: Storage investigations 1921-22. Marble Lab., Inc. Rept.2, Canton, PA. p. 17-98.

Meheriuk, M., R.K. Prange, P.D. Lidster, and S.W. Porritt. 1994. Postharvest disorders of apples and pears. Agr. Can. Publ. 1737/E.

Plagge, H.H. and T.J. Maney. 1937. Factors influencing the development of soggy break-down in apples. J. Agr. Res. 55:759-764.

Smock, R.M. 1977. Nomenclature for internal storage disorders of apples. HortScience 12: 306-308.

Tong, C.B.S., D.S. Bedford, J.J. Luby, F.M. Propsom, R.M. Beaudry, J.P. Mattheis, C.B. Watkins, and S.A. Weis. 2003. Location and temperature effects on soft scald in 'Honeycrisp' apples. HortScience 38:1153-1155.

Wargo, J.M. and C.B. Watkins. 2004. Maturity and storage quality of 'Honeycrisp' apples. HortTechnology 14:496-499.

Watkins, C.B., M. Erkan, J.F. Nock, K.A. Iungerman, R.M. Beaudry, and R.E. Moran. 2005. Harvest date effects on maturity, quality, and storage disorders of 'Honeycrisp' apples. HortScience 40:164-169.

Watkins, C.B., J.F. Nock, S.A. Weis, S. Jayanty, and R.M. Beaudry. 2004. Storage temperature, diphenylamine, and pre-storage delay effects on soft scald, soggy breakdown and bitter pit of 'Honeycrisp' apples. Postharvest Biol. Technol. 32:213-221. 